\title{
Analyses of MPPT Algorithms in Real Test Conditions
}

\author{
Thiago Fialho Guimarães \\ Universidade Tecnológica Federal do Paraná \\ Curitiba, Brazil \\ thiagofialho.vg@gmail.com
}

\author{
Vicente Leite \\ Research Centre in Digitalization and Intelligent Robotics (CeDRI) \\ Polytechnic Institute of Bragança \\ Bragança, Portugal \\ avtl@ipb.pt
}

\begin{abstract}
Maximum Power Point Tracking (MPPT) algorithms are of major importance for optimized yield in gridconnected PV systems. Many algorithms have been investigated. However, most of the works compare these algorithms based on a literature review or on simulation. This paper presents an experimental analysis of MPPT techniques: two of the simplest (Perturb \& Observe and Incremental Conductance) and two of the most complex (Fuzzy Logic Controller and Particle Swarm Optimization). The results are carried out in real test conditions, with and without shadow. The power converter is based on a boost converter and a voltage source inverter. The control is implemented using Simulink ${ }^{\circledR}$ and dSPACE 1103 real-time controller board. Moreover, the MPPT techniques of three commercial string inverters are also analysed.
\end{abstract}

Keywords- MPPT, Perturb \& Observe, Incremental Conductance, Fuzzy Logic Controller, Particle Swarm Optimization.

\section{INTRODUCTION}

The two biggest difficulties in the generation of photovoltaic (PV) systems are the low conversion efficiency of the electric potential and the high cost of PV cells [1]. However, meteorological conditions must be considered, since PV cells have non-linear I-V characteristics, which change with variation in radiation, temperature and load [2]. Due to these characteristics, the maximum power point (MPP) changes constantly and is not known. However, it can be found through search algorithms.

A maximum power point tracking algorithm (MPPT) aims to keep the PV modules operating in the MPP, regardless of the load and weather variations [3]. A MPPT algorithm improves the annual yield of every PV string or module. Extensive research has been done during last decade. Dozens of algorithms have been investigated $[4,5]$, from the simplest ones [6] to the most complex [7,8]. Many studies are dedicated to comparative analysis. With a few exceptions [9], most are based on a review of previous works $[4,7]$ or, at most, on simulation $[6,10]$. Some previous works are not conclusive about the benefits of intelligent algorithms compared to the simplest ones, considering their drawbacks [7]. This work compares two well-known MPPT algorithms, Perturb \& Observe (P\&O) and Incremental Conductance (IC), with two intelligent algorithms, Fuzzy Logic Controller (FLC) and Particle Swarm Optimization (PSO). This comparison is based on experimental analysis. Furthermore, three commercial PV inverters, from different manufacturers, are also analyzed regarding their MMPT algorithms.

\section{OVERVIEW OF MPPT TECHNIQUES}

In general, MPPT algorithms work by combining load impedance with source impedance, thus finding MPP and transferring maximum power. This technique consists of controlling a DC-DC converter to perform the impedance matching [11].

Among the MPPT algorithms proposed in the literature, this work evaluates the performance of four techniques that are among the most discussed, such as Perturb \& Observe, Incremental Conductance, Fuzzy Logic Controller and Particle Swarm Optimization. The choice of these algorithms allows the analysis of techniques with different types of approaches and levels of complexity under the same test conditions.

\section{A. Perturb \& Observe}

The MPPT Perturb and Observe (P\&O) algorithm is one of the simplest and most discussed techniques in the literature [1]. This technique applies a small disturbance to the system in order to follow the path that leads to the MPP.

In the flowchart of Fig. 1 it is possible to observe the steps of the MPPT P\&O algorithm. The first steps are to read the voltage and current and to calculate the power of the PV string. After the acquisition of the signals, at time $t_{\mathrm{k}}$, the power and voltage values are compared with the respective previous samples, at $t_{\mathrm{k}-1}$, and based on this information the path to the MPP is chosen [12].

When there is an increase or decrease in voltage, thus imposing a small disturbance, the operating point of the PV string changes and, consequently, the extracted power [12]. If this power change is positive, the algorithm continues to increase the voltage, but if the power change is negative, it indicates that the MPP is in the opposite direction, so the algorithm starts to reduce the voltage to reach the MPP. In this way, part of the P-V curve is covered by small constant steps, that is, by small disturbances to find the MPP.

In this case, as shown in the flow chart of Fig. 1, the disturbance is made every second, being controlled by the voltage with a $3 \mathrm{~V}$ step $(\Delta \mathrm{V})$. The choice of these values is made according to the voltage range.

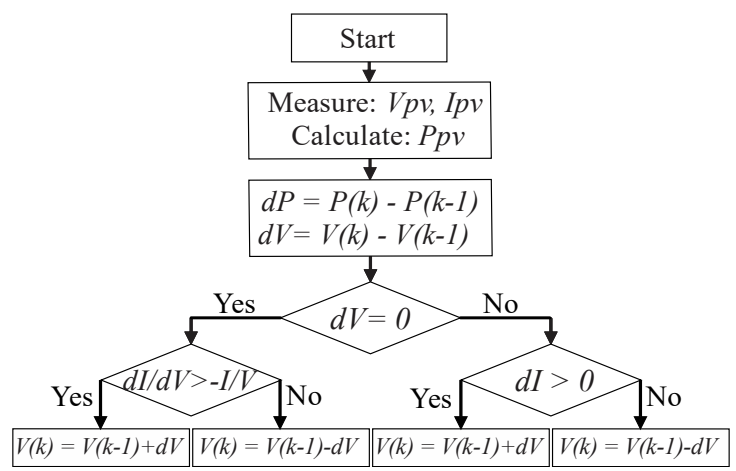

Fig. 1. Flowchart of MPPT P\&O algorithm. 


\section{B. Incremental Condutance}

The MPPT Incremental Conductance (IC) algorithm, like $\mathrm{P} \& \mathrm{O}$, applies a small disturbance to the system to follow the path that leads to the MPP [1]. What differentiates the two techniques are the parameters used for decision, which in the IC algorithm are conductance (1) and incremental conductance (2).

$$
\begin{gathered}
G G=I_{p v} / V_{p v} \\
\Delta G G=\Delta I_{p v} / \Delta V_{p v}
\end{gathered}
$$

The decision to increase or decrease the voltage is made based on (1) and (2). Let us take as an example a P-V or P-I characteristic curve of a PV string. When the operating point is on the left of the MPP, the value of the derivative of the curve assumes a negative value. On the contrary, if it is on the right of the MPP, the derivative takes on a positive value. When working on the MPP, it takes on a zero value, as shown in (3).

$$
\begin{cases}\Delta G G=-G G, & \text { in MPP } \\ \Delta G G>-G G, & \text { on the left } \\ \Delta G G<-G G, & \text { on the right }\end{cases}
$$

The algorithm compares the conductance and the incremental conductance to decide when to increase or decrease the PV voltage to track the MPP, as shown in the flow chart of Fig. 2. In this case, the disturbance is done at every second, being controlled by the voltage, with a $3 \mathrm{~V}$ step $(\Delta \mathrm{V})$. These values are chosen according to the voltage range.

\section{Particle Swarm Optimization}

Particle Swarm Optimization (PSO) is a technique that uses stochastic variables based on a population for solving optimization problems [13].

The PSO algorithm was not designed for applications in PV systems. However, it can be adapted for this new purpose. This technique works by researching the space of a function, adjusting the position of each particle [14]. In a PV application, it boils down to adjust the duty cycle of the DC$\mathrm{DC}$ converter for each particle at a point on the P-V curve. At the end of each cycle, the position of each particle is adjusted by a speed factor given by (4) and the result is given by (5).

$$
\begin{gathered}
\left.v_{i}(t+1)=w v_{i}(t)+c_{1} R_{1}\left(p_{b i}(t)-d_{i}(t)\right)\right)+c_{2} R_{2}\left(G_{b}(t)-d_{i}(t)\right) \\
d_{i}(t+1)=d_{i}(t)+v_{i}(t+1)
\end{gathered}
$$

Where $v_{i}$ is the velocity of particle $i, c_{1}$ and $c_{2}$ are the acceleration constants, $w$ is the weight of inertia, $R_{1}$ and $R_{2}$ are

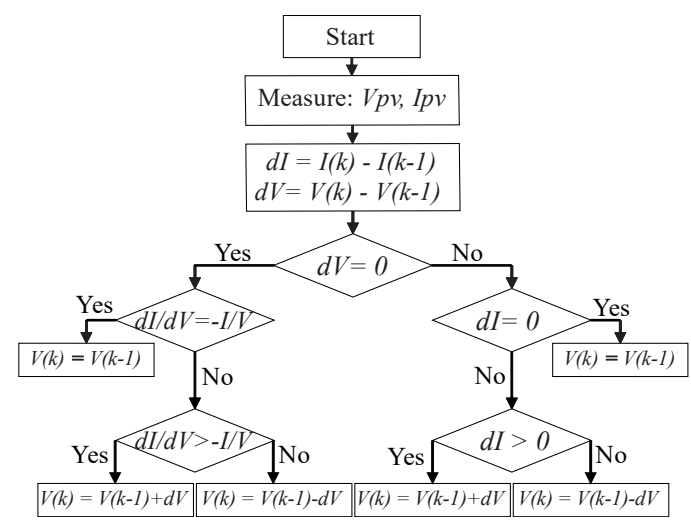

Fig. 2. Flowchart of MPPT IC algorithm. random values between 0 and $1, p_{b i}$ is the location with the best fitness of all the visited location of particle $i, d_{i}$ is the position of particle $i$, and $G_{b}$ is the best position found.

With the flowchart shown in Fig. 3, it is possible to observe the steps of the PSO algorithm in each iteration of the process. This was the PSO algorithm implemented in this work. Four particles and a delay of $100 \mathrm{~ms}$ are used for each iteration. The values of the constants used in (4) were $w=0.4$, $c_{1}=1.2$ and $c_{2}=2$.

\section{Fuzzy Logic controll}

The Fuzzy Logic Control (FLC) algorithm, as shown in Fig. 4, generally consists of three stages: fuzzification, rule base and defuzzification [11]. During fuzzification, the numeric input variables are converted to linguistic variables based on a membership function [11]. Generally, the inputs for a diffuse logic MPPT controller are voltage variation $\Delta V_{p v}$ (6) and power variation $\Delta P_{p v}(7)$.

$$
\begin{gathered}
\Delta V_{p v}=V_{p v}(t)-V_{p v}(t-1) \\
\Delta P_{p v}=\Delta V_{p v} \times \Delta I_{p v}
\end{gathered}
$$

In this work, in the fuzzification stage, five triangular association functions were used for the inputs and output. The two input variables were converted to linguistic values: Negative Big (NB), Negative Small (NS), Zero (ZE), Positive Small (PS), and Positive Big (PB). The membership functions of inputs and the output are shown in Fig. 5.

Mamdani's method is used for fuzzy inference. For defuzzification, the centroid method was used to calculate the $\Delta V_{\text {ref }}$ output. The rule base used to find the output is shown in the table of Fig. 5, where the reference voltage for the PI controller $\left(V_{\text {ref }}\right)$ is calculated based on (8).

$$
V_{r e f}=V_{p v}+\Delta V_{r e f}
$$

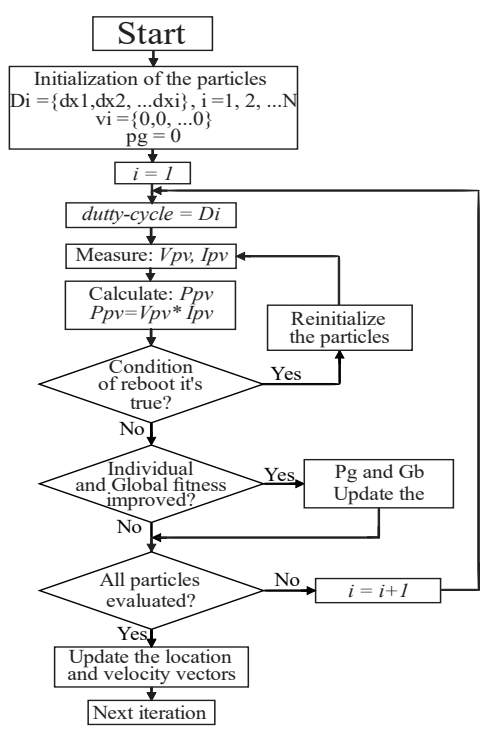

Fig. 3. Flowchart of MPPT FLC algorithm.

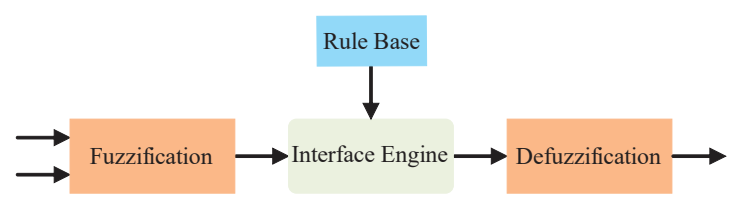

Fig. 4. Flowchart of MPPT FLC algorithm. 
In the defuzzification stage, the fuzzy logic controller output is converted to a controller variable. In this case, it is the voltage reference $\left(V_{r e f}\right)$ used in a PI controller. Fuzzy logic controllers can work with inaccurate inputs, not needing a precise linear mathematical model, but with a high implementation cost.

\section{EXPERIMENTAL PLATAFORM}

For testing the MPPT algorithms, the PV inverter topology shown in Fig. 6 was used. The power topology has a bidirectional DC-DC converter, configured as a boost converter, followed by a voltage source inverter.

For the control of the boost converter, the MPPT algorithm gives the input voltage reference to PI controller or directly the duty cycle. This imposes the dc output voltage of the PV string. The voltage source inverter controls the power by controlling the dc-link voltage, maintaining the voltage on the DC bus at $400 \mathrm{~V}$, higher than the peak voltage of the grid. The control of the current injected into the grid is based on voltageoriented control $[15,16]$.

\section{A. Experimental set-up}

The power structure, shown in Fig.7, is based on the Powerex PM75RLA120 intelligent power module, with a 3phase IGBT voltage source inverter. A leg is used for the boost converter, where one of the IGBTs always remains off, functioning as a diode, while the other semiconductor is controlled by the MPPT algorithm. The remaining two legs are used as a single-phase voltage source inverter, which is controlled by voltage-oriented control.

The MPPT algorithms and the voltage oriented control were implemented in Simulink ${ }^{\circledR}$. Then, dSPACE 1103 realtime controller board and ControlDesk ${ }^{\circledR}$ application were used for the real-time control.

\section{B. PV Strings}

For the tests, two PV strings were used, shown in Fig. 8, which are formed by PV modules of different number and
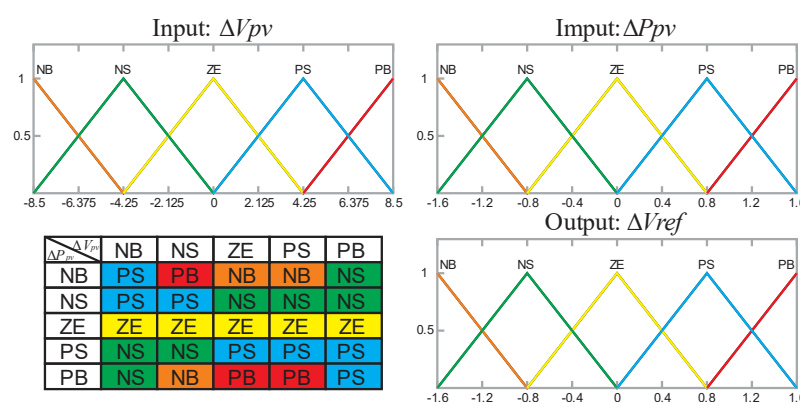

Fig. 5. Membership functions.

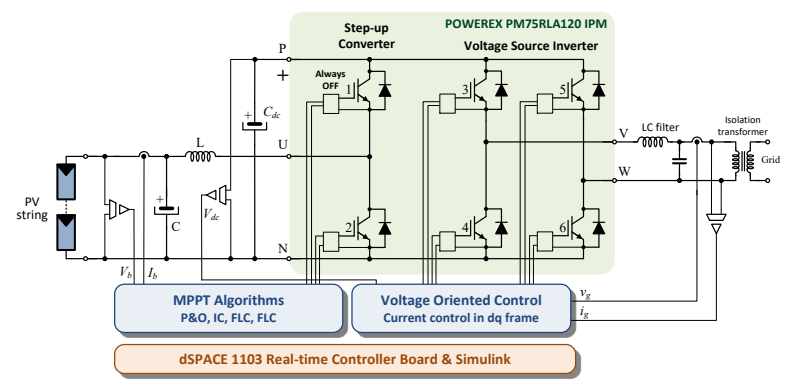

Fig. 6. Power topology. model. For tests under normal conditions, two strings A and B were used. The first is composed by 5 Fluitecnik FTS220P modules. The second, is composed by 3 REC Solar REC275PE modules and was used in tests with partial shading.

The individual characteristics of the two PV modules used are shown in Table I. Both models have 60 PV cells and a bypass diode every 20 cells.

TABLE I. ChARACTERISTICS OF Photovoltaic Models

\begin{tabular}{|c|c|c|c|c|c|}
\hline PV modules of & Max. Power & $\boldsymbol{I}_{\boldsymbol{S C}}$ & $\boldsymbol{V}_{\boldsymbol{O O C}}$ & $\boldsymbol{I}_{\boldsymbol{M P P}}$ & $\boldsymbol{V}_{\boldsymbol{M P P}}$ \\
\hline String A & $220 \mathrm{~W}$ & $8.30 \mathrm{~A}$ & $36.76 \mathrm{~V}$ & $7.51 \mathrm{~A}$ & $29.38 \mathrm{~V}$ \\
\hline String B & $275 \mathrm{~W}$ & $9.25 \mathrm{~A}$ & $38.70 \mathrm{~V}$ & $8.74 \mathrm{~A}$ & $31.50 \mathrm{~V}$ \\
\hline
\end{tabular}

The MPPT algorithms are evaluated in different situations: tests under normal conditions and tests with partial shading.

The tests under normal conditions were carried on clean days. During these tests the irradiation does not suffer sudden changes, and the same happens with the P-V curve of the PV string, which has only a MPP, as shown by the blue curves of Fig. 9. These are the normal conditions for the operation of a PV system.

The tests in partial shading conditions evaluate MPPT algorithms when there is shadow on part of the PV string surface. Therefore, the irradiation is not the same in all cells, and the module is under partial shading. Thus, the curve may have more than one maximum, which makes the work of the algorithms more difficult, since only one of these maximums is the MPP. An example of partial shading, in a generic way, is illustrated by the red curves of Fig. 9 .

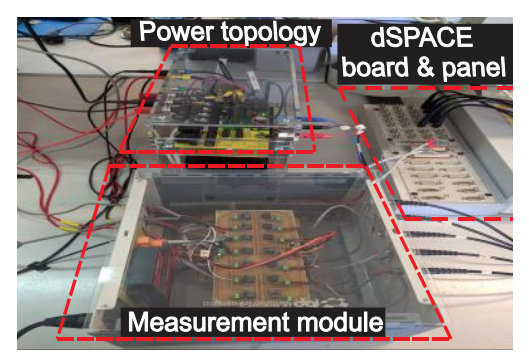

Fig. 7. Experimental set-up.

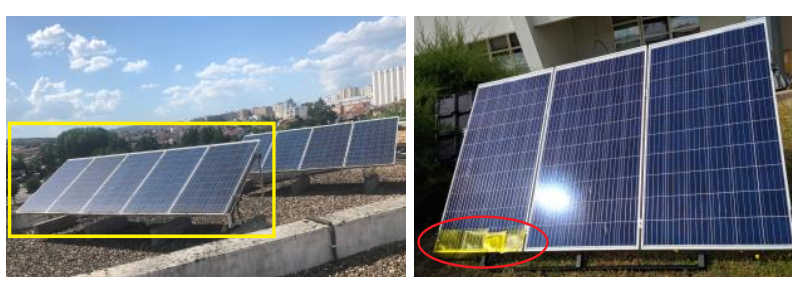

Fig. 8. String A (at left) and string B (at right).
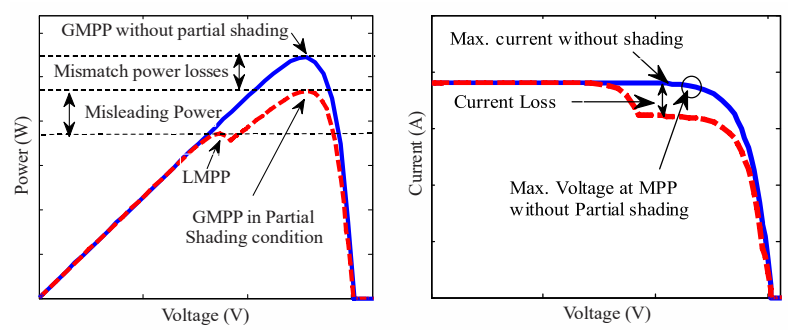

Fig. 9. Generic PV curves: P-V (on the left) and I-V (on the right). 


\section{EXPERIMENTAL RESULTS}

The experimental results are divided into three groups, according to tests under normal conditions, tests with partial shading and tests with commercial inverters. During each test, the performance of each algorithm is verified individually.

\section{A. Tests Under Normal Conditions}

During clean days, irradiation does not suffer sudden changes. The same happens with the PV curve of the PV arrangement, remaining almost constant and with only a maximum, as shown in the blue curves of Fig. 9. These are the normal operating conditions expected for a PV system.

Tests under normal conditions (with string A) evaluate the algorithms in a clean day, with radiation and temperature almost constant during the test. The results are shown in Fig. 10 to Fig. 13. At the beginning, a P-V curve is traced. Thus, $65 \%$ of the $\mathrm{P}-\mathrm{V}$ curve is acquired, around $V_{M P P}$, in order to identify the MPP. During this process, and with the PSO, the string output voltage is imposed by increasing the duty cycle linearly from 0.4 to 0.9 . Therefore, the string output voltage decreases from a value above the MPP to a value below the MPP, as can be seen in Fig. 12. With the other algorithms, the string output voltage is linearly increased from

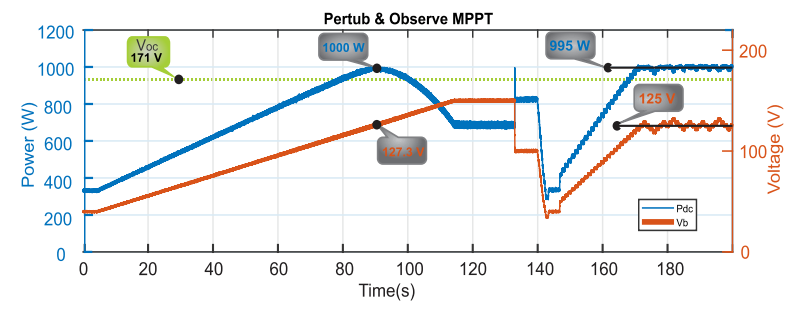

Fig. 10. Test under normal conditions of the $\mathrm{P} \& \mathrm{O}$ algorithm.

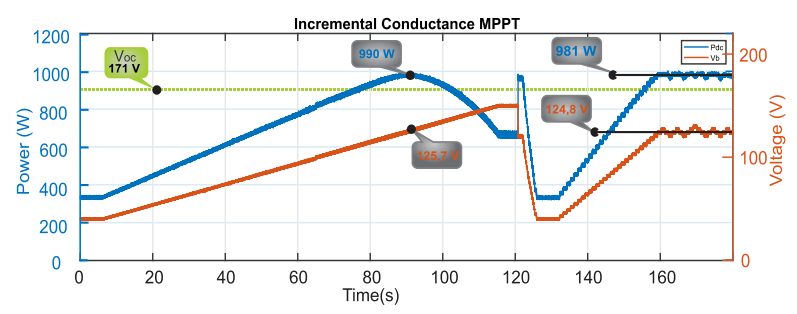

Fig. 11. Test under normal conditions of the IC algorithm.

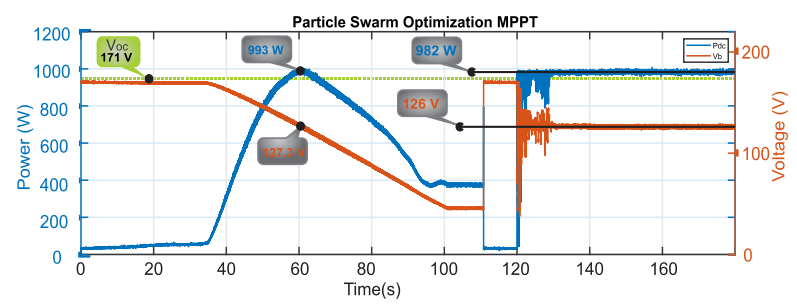

Fig. 12.Test under normal conditions of the PSO algorithm.

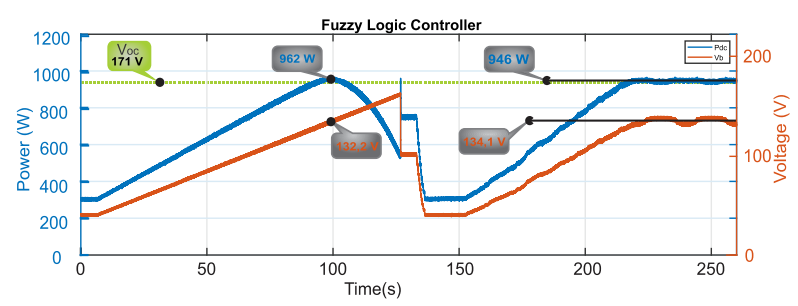

Fig. 13. Test under normal conditions of the FLC algorithm.
$40 \mathrm{~V}$ to $150 \mathrm{~V}$. After the acquisition of the $\mathrm{P}-\mathrm{V}$ curve around MPP, the algorithms are enabled, always starting at $40 \mathrm{~V}$, as shown in Fig. 10, Fig. 11 and Fig. 13.

\section{B. Test in partial shading conditions}

This second test uses string B, because it is easier to shade part of the modules since it is on the ground in front of the laboratory. One of the three PV modules was partially shaded (as shown in Fig. 8). At the beginning, a P-V curve is traced as for tests $\mathrm{A}$. After the acquisition of the $\mathrm{P}-\mathrm{V}$ curve around MPP, the algorithms are enabled, always starting at $40 \mathrm{~V}$, as shown in Fig. 14 to Fig. 17.

\section{Tests with commercial inverters}

The purpose of these tests is to evaluate the MPPT algorithms of three commercial inverters available in the laboratory: Solis mini 700 with string A, and Sunny Boy SB1.5 and PIKO MP with string B. The strings were chosen according to the rated characteristics of the inverters. During this test, the photovoltaic string is connected to inverter and the dc voltage and current are acquired using the same set-up. The results, from the initialization until the steady-state operation around MPP, are shown in Fig. 18 to Fig. 20.

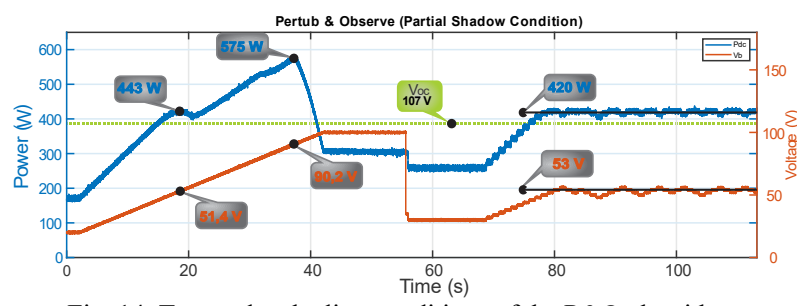

Fig. 14. Test under shading conditions of the $\mathrm{P} \& \mathrm{O}$ algorithm.

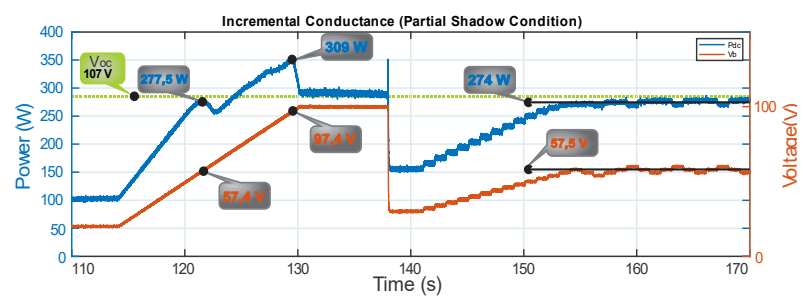

Fig. 15. Test under shading conditions of the IC algorithm.

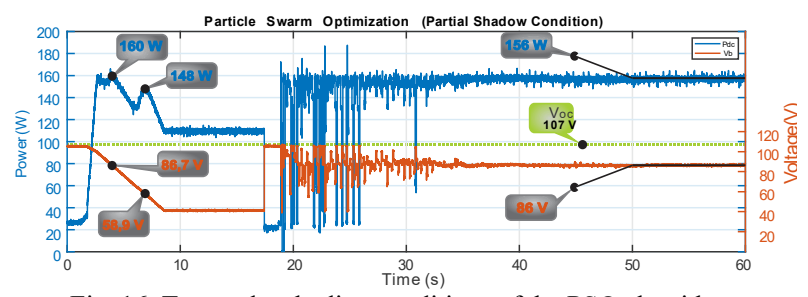

Fig. 16. Test under shading conditions of the PSO algorithm.

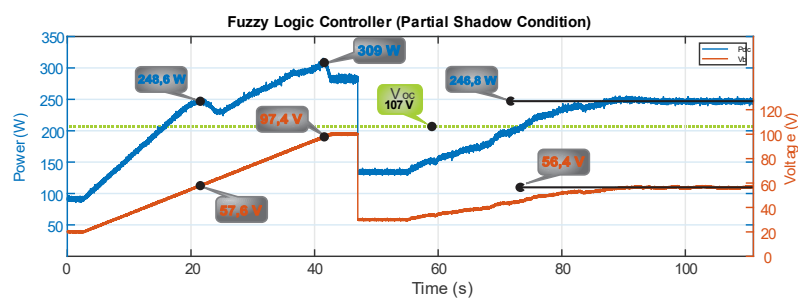

Fig. 17. Test under shading conditions of the FLC algorithm. 


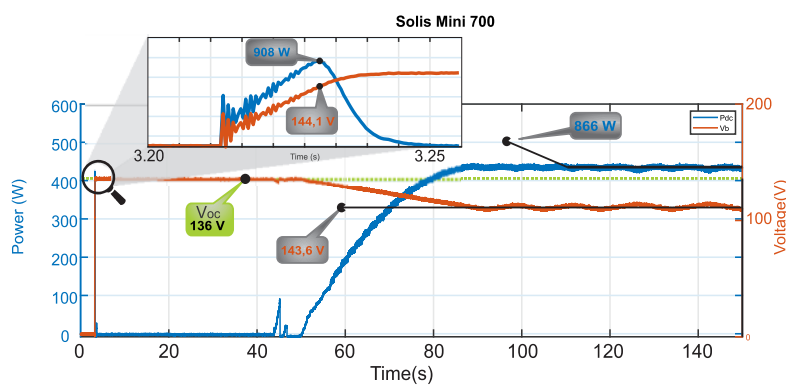

Fig. 18. Results with commercial inverter Solis Mini 700.

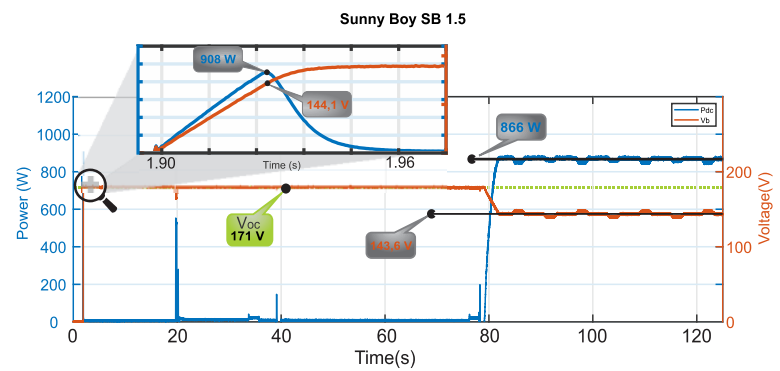

Fig. 19. Results with commercial inverter Sunny Boy SB 1.5.

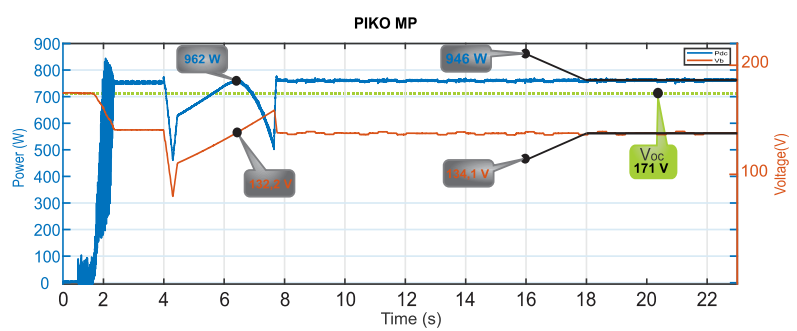

Fig. 20. Results with commercial inverter Piko MP.

\section{DISCUSSION}

With the tests carried out, it is possible to compare some characteristics of the algorithms, such as precision in reaching the MPP, oscillation in the MPP and the ability to deal with partial shading problems.

\section{A. Ability to achieve the MPP}

There is a single point of operation of the PV string that corresponds to the MPP. For an algorithm to reach exactly that point it is not so simple. The closer to the MPP the algorithm operates, the more power is extracted from the PV string. The $\mathrm{P}-\mathrm{V}$ curve drawn in the tests under normal conditions, before the initialization of each MPPT algorithm, can be used to measure how close to the MPP each technique can operating. With the test data, using (9), where $V_{M P P}$ is the voltage at the MPP of the P-V curve and $V_{M P P T}$ is the point at which the algorithm operates.

$$
\text { Precision }=100 *\left(1-\left(\left(V_{M P P}-V_{M P P T}\right) / V_{M P P}\right)\right.
$$

Using (9), the values shown in Table II were found.

TABLE II. PRECISION OF MPPT TECHNIQUES

\begin{tabular}{|c|c|c|c|}
\hline $\boldsymbol{P \& O}$ & $\boldsymbol{I C}$ & $\boldsymbol{P S O}$ & $\boldsymbol{F L C}$ \\
\hline $98,2 \%$ & $99,3 \%$ & $99,0 \%$ & $98,6 \%$ \\
\hline
\end{tabular}

\section{B. Oscillation around the MPP}

One of the factors that imply the efficiency of the algorithm is the oscillation around the MPP, as it results in loss of power. Using the test results under normal conditions it is possible to measure this oscillation. The graphs in Fig. 21 to

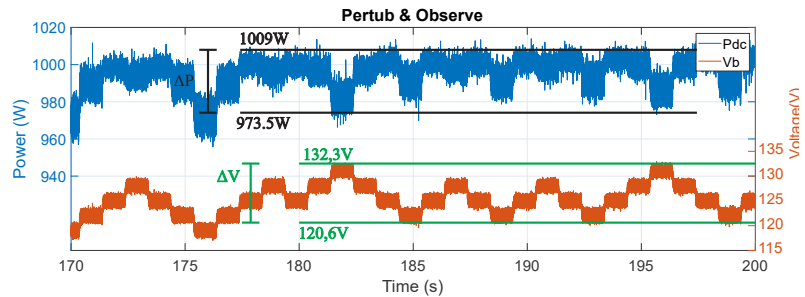

Fig. 21. Oscillation of the P\&O algorithm in MPP.

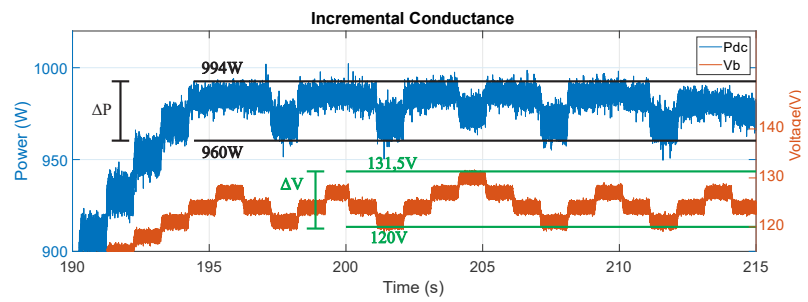

Fig. 22. Oscillation of the IC algorithm in MPP.

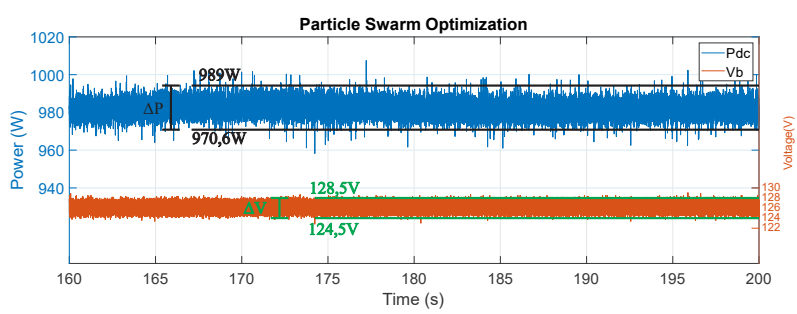

Fig. 23. Oscillation of the PSO algorithm in MPP.

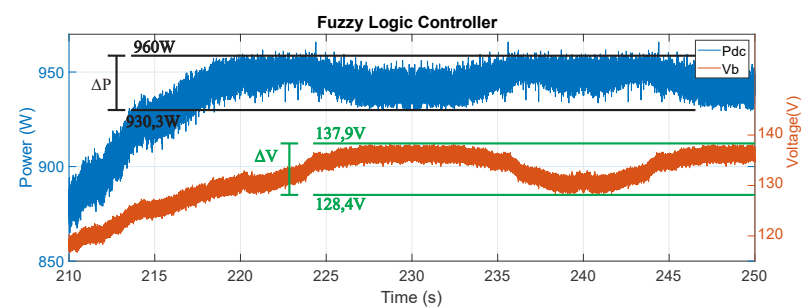

Fig. 24. Oscillation of the FLC algorithm in MPP.

Fig. 24 are a zoom of the graphs in Fig. 10 to Fig. 13 when the algorithm has already reached the MPP, which allows to know how much is the oscillation.

The values of the power and voltage oscillations of all implemented algorithms are shown in Table III.

TABLE III. POWER AND VOLTAGE OSCILATION IN THE MPP

\begin{tabular}{|c|c|c|c|c|}
\hline & $\boldsymbol{P \& O}$ & $\boldsymbol{I C}$ & $\boldsymbol{P S O}$ & $\boldsymbol{F L C}$ \\
\hline$\Delta P$ & $1,82 \%$ & $1,77 \%$ & $0,95 \%$ & $1,60 \%$ \\
\hline$\Delta V$ & $4,85 \%$ & $4,79 \%$ & $1,61 \%$ & $3,70 \%$ \\
\hline
\end{tabular}

\section{Under parcial shadow}

With the results of the tests under partial shading conditions, as can be seen in Table IV, only the PSO algorithm was able to find the GMPP, while the other algorithms reached only a local maximum.

TABLE IV. ABILITY OF THE ALGORITHMS TO DEAL WITH PARTIAL SHADING

\begin{tabular}{|c|c|c|c|}
\hline $\boldsymbol{P \&} \boldsymbol{O}$ & $\boldsymbol{I C}$ & $\boldsymbol{P S O}$ & $\boldsymbol{F L} \boldsymbol{C}$ \\
\hline No & No & Yes & No \\
\hline
\end{tabular}

Therefore, under partial shading conditions, $\mathrm{P} \& \mathrm{O}, \mathrm{IC}$ and FLC are not able to achieve the GMPP. The PSO algorithm is 
the only one of the four evaluated algorithms capable of dealing with partial shading conditions.

\section{Evaluation of commercial inverter algorithms}

As can be seen in the tests of commercial inverters, Fig. 18 to Fig. 20, the three tested equipment have MPPT techniques similar to the P\&O algorithm. This can be explained by the ease of implementation and the robustness of the technique. Moreover, characteristics such as step and perturb frequency are defined according to the range of the input voltage.

\section{CONCLUSION}

This work presents an experimental comparative analysis of four MPPT algorithms of different complexity: Perturb \& Observe, Incremental Conductance, Fuzzy Logic Controller and Particle Swarm Optimization. The first two are simple and widely used and the latest two are more complex. The simplest can be implemented with less processing, but on the other hand, they lose in accuracy. The results obtained under shadow effect, with more than one point of maximum power point, show that only the PSO algorithm is able to find the true maximum power point. Tests carried out with three commercial PV inverters seem to use of simple algorithms, similar to Perturb \& Observe.

\section{REFERENCES}

[1] A. K. Gupta and R. Saxena, "Review on widely-used MPPT techniques for PV applications," 2016 International Conference on Innovation and Challenges in Cyber Security (ICICCS-INBUSH), Noida, 2016, pp. 270-273, doi: 10.1109/ICICCS.2016.7542321.

[2] A. W. Leedy and K. E. Garcia, "Approximation of P-V characteristic curves for use in maximum power point tracking algorithms," 45th Southeastern Symposium on System Theory, Waco, TX, 2013, pp. 8893, doi: 10.1109/SSST.2013.6524945.

[3] Faranda, R.; Leva, S.; Maugeri, V., "MPPT techniques for PV Systems: Energetic and cost comparison," Power and Energy Society General Meeting - Conversion and Delivery of Electrical Energy in the 21st Century, 2008 IEEE , vol., no., pp.1,6, 20-24 July 2008.

[4] Bhatnagar, Pallavee \& Nema, Rajesh. (2013). Maximum Power Point Tracking Control Techniques: State-of-the-Art in Photovoltaic Applications. Renewable and Sustainable Energy Reviews. 23. 224241. 10.1016/j.rser.2013.02.011. (Article)

[5] A. K. Podder, N. K. Roy and H. R. Pota, "MPPT methods for solar PV systems: a critical review based on tracking nature," in IET Renewable Power Generation, vol. 13, no. 10, pp. 1615-1632, 297 2019, doi: 10.1049/iet-rpg.2018.5946. (Article)
[6] A. K. Gupta and R. Saxena, "Review on widely-used MPPT techniques for PV applications," 2016 International Conference on Innovation and Challenges in Cyber Security (ICICCS-INBUSH), Noida, 2016, pp. 270-273, doi: 10.1109/ICICCS.2016.7542321.

[7] M. E. E. Telbany, A. Youssef and A. A. Zekry, "Intelligent Techniques for MPPT Control in Photovoltaic Systems: A Comprehensive Review," 20144 th International Conference on Artificial Intelligence with Applications in Engineering and Technology, Kota Kinabalu, 2014, pp. 17-22, doi: 10.1109/ICAIET.2014.13.

[8] Motahhir, Saad \& Aoune, Ayoub \& Abdelaziz, el ghzizal \& Sebti, Souad \& Derouich, Aziz. (2017). Comparison between Kalman filter and incremental conductance algorithm for optimizing photovoltaic energy. Renewables: Wind, Water, and Solar. 4. 8. 10.1186/s40807017-0046-8

[9] M. A. G. de Brito, L. Galotto, L. P. Sampaio, G. d. A. e Melo and C. A. Canesin, "Evaluation of the Main MPPT Techniques for Photovoltaic Applications," in IEEE Transactions on Industrial Electronics, vol. 60, no. 3, pp. 1156-1167, March 2013, doi: 10.1109/TIE.2012.2198036.

[10] V. K. Viswambaran, A. Ghani and E. Zhou, "Modelling and simulation of maximum power point tracking algorithms \& review of MPPT techniques for PV applications," 20165 th International Conference on Electronic Devices, Systems and Applications (ICEDSA), Ras Al Khaimah, 2016, pp. 1-4, doi: 10.1109/ICEDSA.2016.7818506.

[11] D. Haji and N. Genc, "Fuzzy and P\&O Based MPPT Controllers under Different Conditions," 2018 7th International Conference on Renewable Energy Research and Applications (ICRERA), Paris, 2018, pp. 649-655, doi: 10.1109/ICRERA.2018.8566943.

[12] M. Kamran, M. Mudassar, M. R. Fazal, M. U. Asghar, M. Bilal, R. Asghar, Implementation of improved Perturb \& Observe MPPT technique with confined search space for standalone photovoltaic system, Journal of King Saud University - Engineering Sciences, 2018, ISSN 1018-3639, https://doi.org/10.1016/j.jksues.2018.04.006.

[13] K. Ishaque, Z. Salam, M. Amjad and S. Mekhilef, "An Improved Particle Swarm Optimization (PSO)-Based MPPT for PV With Reduced Steady-State Oscillation," in IEEE Transactions on Power Electronics, vol. 27, no. 8, pp. 3627-3638, Aug. 2012, doi: 10.1109/TPEL.2012.2185713.

[14] R. B. A. Koad, A. F. Zobaa and A. El-Shahat, "A Novel MPPT Algorithm Based on Particle Swarm Optimization for Photovoltaic Systems," in IEEE Transactions on Sustainable Energy, vol. 8, no. 2, pp. 468-476, April 2017, doi: 10.1109/TSTE.2016.2606421.

[15] V. Leite, Â. Ferreira and J. Batista, "Bidirectional vehicle-to-grid interface under a microgrid project," 2014 IEEE 15th Workshop on Control and Modeling for Power Electronics (COMPEL), Santander, 2014, pp. 1-7, doi: 10.1109/COMPEL.2014.6877175.

[16] Breve M.M., Leite V. (2020) Control of a Bidirectional Single-Phase Grid Interface for Electric Vehicles. In: Nesmachnow S., Hernández Callejo L. (eds) Smart Cities. ICSC-CITIES 2019. Communications in Computer and Information Science, vol 1152. 